\section{Relevance, probative value, and explanatory considerations}

\section{Gustavo Ribeiro}

Harvard Law School, Cambridge, USA
The International Journal of Evidence \& Proof 2019, Vol. 23(I-2) 107-II3 (C) The Author(s) 2019 Article reuse guidelines: sagepub.com/journals-permissions DOI: I0.1 I77//3657|27/88/6740 journals.sagepub.com/home/epj

๑SAGE

\begin{abstract}
In my short contribution to this issue, I focus on Allen and Pardo proposal to redefine key evidentiary concepts in explanatory terms, with special attention to 'relevancy' and 'probative value'. I also join forces with Allen and Pardo in replying to critics to explanatory approaches to evidence law.
\end{abstract}

\title{
Keywords
}

relevance, Probative Value, Explanation

\section{Introduction}

'Relative plausibility and its critics' is Ron Allen and Mike Pardo's latest installment in a series of welcomed efforts to reshape American and international evidence scholarship from a probabilistic framework to one based on explanatory considerations (see e.g. Allen and Pardo, 2007a; Pardo and Allen, 2008). Among many invaluable contributions to the explanatory camp over the last decade, Allen and Pardo have helped us better understand key evidentiary concepts in explanatory terms (see Allen and Pardo, 2019). In my short contribution to this issue, I focus on that aspect of their enterprise with special attention to the concepts of 'relevancy' and 'probative value'. I also join forces with Allen and Pardo in replying to critics to explanatory approaches to evidence law.

\section{Key evidentiary concepts in explanatory terms}

Relevance. For Allen and Pardo, a piece of evidence is relevant 'if it is explained by the particular explanation offered by the party offering the evidence' (See Pardo, 2013; Pardo and Allen, 2008: 241-242). This definition has clear advantages over probabilistic formulations, according to which relevancy is a function of likelihood ratios. ${ }^{1}$ As Allen has taught us, it is common for opposing sides in a trial to present competing accounts of events that share the same features. To use Allen's example,

1. See Allen \& Pardo (2019: 11, fn 41) (citing, among others, Lempert (1977)).

\section{Corresponding author:}

Gustavo Ribeiro, Gustavo Ribeiro, Boston University, Boston, MA.

E-mail: gustavor@bu.edu 
the fact that the accused drove to a town on a day and time is consistent with the prosecution's case that he was driving there to commit murder and with the defendant's case that he was driving there to visit his mother. Since this fact is consistent with both sides' explanations, it leaves the respective likelihood ratios unchanged. Still, most courts would consider that evidence as legally relevant. So, a definition anchored in likelihood ratios fails to capture all elements of the legal concept of relevancy.

There are, however, at least two problems with Allen and Pardo's formulation of relevancy. First, their account does not provide a necessary condition for a sound concept of relevancy. A piece of evidence $E$ may still be relevant to hypothesis $H$ even if $H$ does not correctly explain $E$. For instance, the evidence that John has a chest wound may be relevant evidence for the hypothesis that John will die, even though the hypothesis that he will die does not explain why John has the chest wound (see Achinstein, 1978). Nor can this account provide a sufficient condition for relevancy. Suppose my scooter will not start on a cold winter morning in Massachusetts (see Achinstein, 1978). The hypothesis $H$ that 'At precisely 3:05 AM this morning, two boys removed the gas remaining in my tank and substituted it with water,' would, if true, correctly explain my evidence that my scooter does not start. Yet it seems that my evidence is not relevant to assess $H$ 's truth. In fact, it seems $E$ cannot be evidence at all for $H$, let alone relevant evidence. Given what we know about motor engines, batteries, and cold weather, my evidence is not a good reason to believe in $H^{2}$ Otherwise, we would be forced to claim that the fact that my scooter will not start on a cold winter morning in Massachusetts is relevant evidence for a vast range of hypotheses closely related to $H$, such as: 'At precisely 5:03 AM, three monkeys removed the gallon of gas remaining in my tank and substituted crushed bananas.' The fact that my scooter will not start does not give us a good reason to believe in either of these far-fetched hypotheses. So, $E$ may still not be relevant evidence even if it is explained by $H$. As a result, Allen and Pardo's formulation provides neither a necessary nor a sufficient condition for relevancy.

Here I want to focus on the second problem with Allen and Pardo's formulation of relevancy, namely the fact that it leaves out one important aspect of the concept as understood in the American legal tradition.

According to the test for relevancy under Federal Rule of Evidence ('FRE') 401, evidence is relevant if it has any tendency to make a fact more or less probable. ${ }^{3}$ Allen and Pardo's formulation does not allow for the possibility that a piece of evidence can make a fact less probable. ${ }^{4}$ Here is why. Allen and Pardo seem to say that if evidence is explained by an available hypothesis (and therefore makes that hypothesis more probable), then the evidence should be considered relevant for legal purposes. This is logically equivalent to the following proposition: if a piece of evidence is not explained by an evidentiary hypothesis available at the trial, then that evidence is not relevant. But this is at odds with FRE 401. Under the rule, if an evidentiary hypothesis does not explain a piece of evidence, the hypothesis is less probable. Therefore, that evidence is relevant under that FRE 401.

We can build upon these objections to try to develop a revised formulation of relevancy that is both compatible with an explanationist approach and FRE 401. Here is one suggestion: a piece of evidence is legally relevant if it increases or decreases the relative plausibility of a given evidentiary hypothesis (see Ribeiro, 2018). Another way to articulate the same idea: evidence is relevant (and therefore should be admitted) if it makes an evidentiary hypothesis a better or worse explanation. This revised formulation

2. It is sometimes supposed that evidence bears some relationship to what it is reasonable to believe, so that if $\mathrm{E}$ is evidence that $\mathrm{H}$, then, $\mathrm{E}$ is at least some good reason for believing in H. See Achinstein (1978). However, it is unclear whether the legal concept of evidence picks up this relationship.

3. Federal Rule of Evidence 401 states, 'Evidence is relevant if: (a) it has any tendency to make a fact more or less probable than it would be without the evidence; and (b) the fact is of consequence in determining the action.'

4. But see Pardo (2013: 576-577) (arguing that relevance should be understood broadly such that any evidence would count as relevant so long as it provides some reason in support of the conclusion that a proposition of fact material to the case is true or false). 
not only respects the FRE 401 test, but it also places explanatory value as the central element of the test, in line with the explanation-based approach to standards. I explore the consequences of this formulation further in depth in another place.

Probative value. Allen and Pardo have also helped us to avoid the computing and reference class problems involving probabilistic formulations of the concept of probative value. ${ }^{5}$ According to Allen and Pardo, '[p]robative value refers to the strength of the explanation; the most the evidence is explained by ... the party's explanation of the evidence, the greater the probative value'. ${ }^{6}$ While Allen and Pardo's formulation seems to be on the right track, it might still benefit from a small modification. Probative value can be better explained under an explanationist approach as a function of how much the evidence makes a particular explanation better or worse. ${ }^{7}$

The difference between these two formulations might not be immediately obvious. It is true that if a hypothesis explains any additional piece of evidence, that makes it a better explanation-because it can explain more things. But a piece of evidence can still make an explanation better without being explained by it. For instance, mathematical theorems can improve the explanatory value of meteorological models, making the theorems better explanations of the weather. It does not follow, however, that the mathematical theorems are themselves explained by the meteorological models. If anything, the explanation seems runs in the opposite direction. Likewise, that a defendant had strong personal financial interests tied to the victim's death makes explanations of guilt better explanations. Again, however, the inverse does not hold. A hypothesis about who committed the crime and why does not necessarily explain that person's financial interests. These examples show that many facts offered as evidence in trials can contribute to an explanatory value of explanations - i.e. they can make explanations better or worse-without themselves being explained by the hypothesis. To the extent that they do so, they should be thought to have probative value under an explanation-based approach.

Let us look closely at an example brought by Allen and Pardo to defend their formulation of relevancy and probative value (see Pardo and Allen, 2008: 242). Imagine that an expensive necklace is found in a housekeeper's pocket. Suppose the owner testifies that she found the necklace in the employee's pocket. Allen and Pardo say that this testimony is relevant 'because the fact that the [employee] stole the necklace explains the testimony' (see Pardo and Allen, 2008: 242). What I am suggesting is that the testimony is relevant because it makes the hypothesis that the employee stole the necklace a better explanation, not because the evidence is explained by this hypothesis. According to Allen and Pardo, the testimony's probative value depends on how well the testimony is explained by the justification that the employee stole the necklace. Instead, it might make more sense to measure the testimony's probative value by how much better or worse it makes the explanation that the employee stole the necklace. ${ }^{8}$

Allen and Pardo make an additional important point when addressing the probative value of the testimony in this example:

[i]f there is other evidence that someone stole the necklace, then the testimony has greater probative value; if there is other evidence that the owner gave the [employee] the necklace as a gift, then the testimony has less probative value. (Pardo and Allen, 2008)

5. Allen and Pardo (2007b: 308). For a discussion of probative value as likelihood ratios, see, e.g. Nance and Morris (2002) and Finkelstein and Levin (2003).

6. For a further discussion on the limitation of probability-based approaches to explain probative value, see Ribeiro (2018).

7. Note this is not the same definition as the one given above for relevancy. Briefly, relevancy is related to whether a piece of evidence makes an evidentiary hypothesis better or worse, while probative value is related to how much that evidence makes that same evidentiary hypothesis better or worse.

8. Allen and Pardo make an additional important point when addressing the probative value of the testimony in this example: '[i]f there is other evidence that someone stole the necklace, then the testimony has greater probative value; if there is other evidence that the owner gave the [employee] the necklace as a gift, then the testimony has less probative value' (Pardo and Allen, 2008). 
Pardo and Allen are correct that the probative value of the testimony depends on what are the other available evidence. However, the type of evidence that affects the testimony's probative value is slightly different from what Allen and Pardo suggest (see Pardo and Allen, 2008). The probative value of the testimony is measured in terms of how much better or worse it makes a particular explanation-for instance, the explanation that the employee stole the necklace. This means that the probative value of a piece of evidence is affected by the evidence available for or against the particular explanation we are addressing. If there is already a wide range of evidence to support the explanation that the employee stole the necklace, then the testimony's probative value is small relative to that explanation. The testimony adds little to that explanation. If, however, there is little or no evidence to support the 'thieving employee' explanation, then the testimony's probative value is greater relative to that explanation.

To determine how the testimony's probative value is affected by any evidence that the owner gave the employee the necklace as a gift, we need to assess the testimony's probative value with relation to the specific 'gift hypothesis'. Now here is the tricky part. If there is already evidence available to support the explanation that the owner gifted the necklace to the employee, then the testimony does not have less probative value, as Allen and Pardo suggest. Rather, the testimony would be more probative. Why? Simple - the testimony does not support that explanation. Instead, the testimony weakens it (i.e., makes it a worse explanation). Why? Because here there is no 'overlap' of evidentiary support, as would be the case if there were evidence available - other than the testimony - for the explanation that the employee stole the necklace. In other words, in relation to the explanation that the owner gifted the necklace, the fact that there is available evidence to support this explanation gives the testimony more probative value. Probative value is never assessed in a vacuum.

\section{Joining forces with Allen and Pardo}

In 'Relative plausibility and its critics', Allen and Pardo talk of the advent of an explanatory approach to evidence as a 'paradigmatic shift' in the disciple. Under the Kuhnian description of such process, no new paradigm emerges without fierce criticism from the status quo. Here, I focus on a narrow set of objections to explanation-based approaches to standards, in general, and to the specific proposals by Allen and Pardo, in particular. My goal is to join forces with Allen and Pardo and help to dissipate commonly held questions or objections to the explanatory enterprise.

I start with a perhaps intuitive point often raised anecdotally in small circles. Some react to explanation approaches to evidence law by claiming that "talk of "worse" and "better" explanations gives free reign to jurors' and judges' subjectivity. ${ }^{9}$ Is that a better way to understand and describe some of our most important legal concepts? With probabilistic approaches, we at least had numbers we could hold onto in the attempt to make things less arbitrary.'

At first, expressions such as of 'best explanation' and 'substantially better explanation' in fact risk being as nebulous as old formulations of standards invoking obscure concepts such as 'moral certainty'. ${ }^{10}$ It is true we have yet to construe a philosophically robust theory of explanation (but see, e.g. Hempel, 1965; Salmon, 1984; Woodward, 2003). However, there are different external criteria that decision-makers can point to to assess the comparative explanatory value of competing explanations. When the explanation-based approach tells triers to decide based on the degree of explanatory value of the available evidentiary hypotheses, it is actually (indirectly) asking triers to look at those different criteria. ${ }^{11}$

9. Allen and Pardo also deal with this type of criticism in Allen and Pardo (2019: 27).

10. See, e.g. Commonwealth v Webster, 59 Mass. 295, 320 (1850); see also Victor v Nebraska, 511 U.S. 1, 38 (1994) (alerting for the 'real possibility that such language would lead jurors reasonably to believe that they could base their decision to convict upon moral standards or emotion in addition to or instead of evidentiary standards').

11. For a detailed discussion on some of the criteria see Ribeiro (2018). 
Moreover, the idea that probability approaches give more precise formulations of standards because it associates numerical thresholds with specific standards is illusory. The relevant literature is filled with discussions regarding the problems of formulating standards in terms of degrees of subjective confidence (see Ribeiro, 2018). These issues include the difficulty individuals have articulating their precise levels of confidence, as well as the mistake of prioritizing subjective confidence over relations of evidential support. Concerns about vagueness in formulating standards in terms of explanatory value are inherent in the standards themselves; not in the specific formulation. ${ }^{12}$ Lack of precision may be a general critique of standards, and less a specific critique of the explanation-based approach.

Another initial objection to explanation-based approaches is that it seems to require the party not carrying the burden of persuasion to put forth its own explanation. This concern is particularly prevalent in criminal cases, where a well-known element of the presumption of innocence is that criminal defendants do not have to produce evidence against themselves. This objection misses the mark, however. Nothing in the explanationist approach demands that both parties present explanations of the evidence or any evidence at all for that matter. Every explanation brings with its denial as a necessary contrastive explanation. When my doctor says that the fact that I hit my toe explains my pain, we can judge that reasoning by reference to an explanation that 'something else' explains my pain. Still, it is highly unlikely that in any given case triers will end up with only one explanation put forth by the party carrying the burden of persuasion. Not only are triers free to craft their explanations of the admitted evidence (even though the law might limit which kind of explanation they are allowed to consider), but it is also likely that the opposing party will present her explanation of the evidence. Just because that party is not legally required to do so, does not mean that is the best legal strategy.

A stronger objection against the explanationist approach is that it might incentivize parties to overload courts with evidence. This is because parties (and their councillors) would see their function as construing overreaching narratives. Therefore, they would be more inclined to offer evidence that speaks to parts of the narratives, but is only marginally (if at all) related to controversial facts in the case. This 'evidence saturation' could, in turn, make legal decision-making more complex to the point of making the entire explanation-based approach ultimately unworkable. Even if we concede that the approach creates these incentives, other evidentiary mechanisms can help avoid evidence saturation, so that the approach will not become unworkable. Admissibility and exclusionary rules are the best examples. Not only do we have a vast range of rules that turn evidence inadmissible for a myriad of different reasons, but we also have a catch-all exclusionary clause included in FRE 403.

Larry Laudan has raised a more serious objection (Laudan, 2007). He argued that explanationist standards have little to do with the defining features of IBE. Consider 'beyond a reasonable doubt'. Allen and Pardo have suggested that in criminal cases fact-finders should infer the defendant's guilt only when there is a no plausible explanation consistent with innocence (assuming there is a plausible explanation consistent with guilt) (see e.g. Allen and Pardo, 2007a; Pardo and Allen, 2008). To Laudan, however, this sounds nothing like IBE. It sounds instead like an 'inference to the only plausible explanation' (Laudan, 2007).

This provocation is unfair to proponents of explanation-based approaches. While the reasoning an explanation approach asks of triers about some standards is not, technically speaking, IBE as professional philosophers use the expression; we should not fetishize terminology. Call it inference to [fill in the blank]. The significant contribution of explanation-based approaches is to draw our attention to the role that explanatory inferences play in legal reasoning in general, and how these inferences can shed light on the way we think about standards of proof, in particular. Laudan seems to miss the bigger picture. ${ }^{13}$ 


\section{Conclusion}

Perhaps the most important contribution by Ron Allen and Mike Pardo in 'Relative plausibility and its critics' is to clear the path for future research from uninformed misunderstandings or misguided criticism regarding the role of explanatory considerations in evidence scholarship. For that, Allen and Pardo deserve all the praise and recognition due. In my short contribution to this issue, I hope to have been able to help further advance the explanatory camp in evidence scholarship in a similar direction.

\section{Author's note}

Lecturer at Boston University Law School and Associate at Greenberg Traurig, LLP. SJD ‘17, Harvard Law School. Excerpts from this article were previous published in volume 22 issue 2 of the International Journal of Evidence and Proof and appear here with permission from the publisher.

\section{Declaration of Conflicting Interests}

The author(s) declared no potential conflicts of interest with respect to the research, authorship, and/or publication of this article.

\section{Funding}

The author(s) received no financial support for the research, authorship, and/or publication of this article.

\section{References}

Achinstein P (1978) Concepts of evidence Mind 87: 22.

Allen RJ (2008) Explanationism all the way down. Episteme 5: 320.

Allen RJ and Pardo MS (2007a) The problematic value of mathematical models of evidence. Journal of Legal Studies 36(1): 107-140.

Allen RJ and Pardo MS (2007b) Probability, explanation and inference: a reply. International Journal of Evidence and Proof 11(4): 307-317.

Allen RJ and Pardo MS (2019) Relative plausibility and its critics. International Journal of Evidence and Proof 23(1-2): 5-59.

Finkelstein M and Levin B (2003) On the probative value of evidence from a screening search. Jurimetrics 43: 265-290.

Hempel CG (1965) Aspects of Scientific Explanation, and Other Essays in the Philosophy of Science. New York: Free Press.

Laudan L (2007) Strange bedfellows: Inference to the best explanation and the criminal standard of proof. International Journal of Evidence and Proof 11: 292-306.

Lempert R (1977) Modeling relevance. Michigan Law Review 75: 1021-1057.

Pardo MS (2013) The nature and purpose of evidence theory. Vanderbilt Law Review 66(2): 547-613.

Nance DJ and Morris SB (2002) An empirical assessment of presentation formats for trace evidence with a relatively large and quantifiable random match probability. Jurimetrics 42: 403-448.

Pardo MS and Allen RJ (2008) Juridical proof and the best explanation. Law and Philosophy 27: 223-268. 
Ribeiro G (2018) Can there be a burden of the best explanation? International Journal of Evidence and Proof 22(2): 91-123.

Salmon WC (1984) Scientific Explanation and the Causal Structure of the World. Princeton, NJ: Princeton University Press.

Woodward J (2003) Making Things Happen: A Theory of Causal Explanation. Oxford: Oxford University Press. 